\title{
A PRÁTICA DE CITAÇÃO EM TRABALHOS ACADÊMICOS
}

\section{(Citation practices in academic writing)}

\author{
Judith C. Hoffnagel \\ (Universidade Federal de Pernambuco - UFPE/NELFE/CNPq) ${ }^{1}$
}

\begin{abstract}
This article examines the citation practices found in texts published in scientific periodicals of Anthropology and Psychology in Portuguese. The differences found in both form and function of the citation practices are attributed to the differences in the nature of scientific investigation and the construction of knowledge in the two disciplines.
\end{abstract}

Key-words: citation, scientific article, Psychology, Anthropology

\section{RESUMO}

Este trabalho examina as práticas de citação encontradas em textos publicados em periódicos científicos brasileiros de Antropologia e de Psicologia. As diferenças encontradas tanto na forma como na função das práticas de citação etão atribuidas às diferenças da natureza da investigação científica e a construção de conhecimento nas duas disciplinas. Palavras-chaves: artigo científico, práticas de citação, Antropologia, Psicologia

\section{Introdução}

Vários estudos em anos recentes têm chamado a atenção para a prática de citação em trabalhos acadêmico-científicos, além de atribuírem a essa prática diferentes funções. Frequentemente,

1. A pesquisa para este artigo foi desenvolvida com apoio do $\mathrm{CNPq}$ (processo $\mathrm{n}^{\circ}$ 301609/2006-3). Os dados foram coletados pelos bolsistas de Iniciação Científica, Lucas de Freitas, Aline Cristina da Silva e Edlamir Coelho da Silva. 
a citação é vista como uma prática padronizada para as ciências em geral, com todas as diferentes áreas de conhecimento seguindo as mesmas convenções de citação. Hoje sabemos que há grandes diferenças de forma e função no uso da citação em áreas de conhecimento distintas. Essas diferenças referem-se também a como, quando e porque um escritor cita, ou seja, referem-se à ação retórica que a citação realiza. Hyland (1999), por exemplo, observa que as diferenças nas práticas de citação indicam distinções no modo que o conhecimento é negociado e confirmado em diferentes comunidades acadêmicas. É neste sentido que a citação serve, entre outras coisas, para desvendar a identidade do escritor/autor e seu grau de pertencimento a uma comunidade discursiva específica.

Meu interesse nas práticas de citação surgiu no âmbito de uma investigação em andamento intitulado "A Escrita: agência e a construção de identidades na pós-graduação” que enfoca o papel da escrita na pós-graduação. Um dos pressupostos dessa investigação é que durante o curso de pós-graduação, ao lado da aquisição de conhecimentos particulares ou específicos a cada área de conhecimento, os alunos de pós-graduação aprenderiam os hábitos de expressão escrita, ou seja, seriam letrados para atuar na sua área específica. Os alunos adotariam práticas discursivas típicas de sua área; aprenderiam a escrever como antropólogos, historiadores, sociólogos, psicólogos, linguistas etc. Em outras palavras, os estudantes deveriam adquirir a competência para se comunicarem através da escrita.

Logo no início da pesquisa, através de entrevistas informais com vários professores da pós-graduação sobre a importância e o papel da escrita, deparei-me com uma velha queixa: os alunos não sabem escrever. Um professor observou que parte da dificuldade é que o aluno não está preparado para "fazer as citações”: Diz o professor :

[...] o aluno chega com muita dificuldade na escrita, na forma de se expressar. Eu também percebo que o aluno que chega diante de um trabalho escrito acadêmico, ele realmente não está preparado pra fazer as citações, pra saber quais são as minhas idéias e as idéias do 
autor. Como eu coloco a idéia do autor como análise própria? Como eu posso juntar duas idéias, que é ainda mais complicado, de dois autores distintos ou de um mesmo autor e qual a minha crítica sobre essas idéias.

A percepção do professor de que o aluno não sabe fazer as citações é uma maneira de dizer que o aluno não conhece ou ainda não adquiriu algumas das práticas retóricas comuns a sua área de conhecimento. A observação do professor me levou a tentar descobrir que papel a prática de citação tem na escrita acadêmica ou científica, e como essa atividade da escrita acadêmica podia contribuir ao desenvolvimento da identidade profissional de um aluno de pós-graduação. Como primeiro passo, precisava saber como a citação é praticada nas diversas áreas do saber.

Existe uma literatura extensa e recente sobre as práticas de citação em textos científicos/acadêmicos em inglês, mas há relativamente pouco sobre essas práticas nos textos científicos escritos em outras línguas. ${ }^{2}$ Investigamos, então, a prática de citação em artigos científicos publicados em periódicos de prestígio de diferentes disciplinas das Ciências Sociais e Humanas no Brasil para descobrir o que o escritor experiente faz quando cita - que ações retóricas são desempenhadas - e, mais especificamente, como citam - que mecanismos lingüísticos são empregados - no intuito de descobrir se há padrões específicos por área disciplinar. Aqui relato os resultados parciais da investigação para as disciplinas de Antropologia e Psicologia. Os dados são provenientes de 32 artigos (16 de cada disciplina) de quatro periódicos (duas de cada disciplina), publicados nos últimos cinco anos. Os periódicos foram escolhidos após consultar professores de antropologia e psicologia sobre quais periódicos consideravam os mais importantes para sua disciplina e em quais gostariam publicar seus próprios trabalhos.

2. Para os estudos em língua portuguesa ver dissertação de Mestrado de Gerencie Ribeiro de Oliveira Cortes (2009). 


\section{A citação}

A citação é vista como prática intertextual que coloca em discussão a experiência científica acumulada, sinalizando a existência de um relacionamento entre os escritores, seus textos e seus leitores (Bazerman, 1988; Hyland, 2000). Em seus estudos sobre a citação, Hyland (2000:21) mostra que a prática textual apropriada é crucial para a aceitação de alegações, tornando a prática da citação central ao contexto social da persuasão no sentido em que pode fornecer justificativas para argumentos e demonstrar a novidade de uma posição, ajudando dessa forma os escritores a estabelecer uma estrutura epistemológica persuasiva para a aceitação de seus argumentos. Para Berkenkotter e Huckin (1995), as citações estabelecem conexões intertextuais que contextualizam um estudo dentro das práticas de construção de conhecimento de uma disciplina

Várias são as funções atribuídas à citação. Permitir, por exemplo, que um escritor se apóia em outros autores para sustentar seu argumento é uma delas. Como autoridade teórica ou metodológica, a reputação do autor citado pode ser reivindicada como suporte para o trabalho do escritor citante. Também, ao reconhecer o débito com estudos precedentes, o escritor citante está se mostrando hábil e fiel a uma comunidade ou orientação particular, criando um espaço retórico para a sua pesquisa e estabelecendo um ethos de credibilidade. Pois como Allen, Qin e Lancaster (1994) nos lembram, o único ambiente no qual uma referência pode ser persuasiva é em uma comunidade, cujos membros compartilham a opinião do escritor sobre a reputação de um cientista citado.

\section{A citação em artigos científicos de antropologia e de psicologia}

Para analisar a citação em 32 artigos científicos, fiz inicialmente um levantamento de todas as citações para ter uma idéia da extensão 
dessa prática nas duas disciplinas. Classifiquei as citações de acordo com sua estrutura de atribuição e o modo como os autores estão referidos sintaticamente. Examinei também como as citações estão incorporadas ao texto (citação direta ou paráfrase) e o uso dos verbos de citação. A Tabela 1 mostra o número de citações encontradas nos 32 artigos.

\section{Tabela 1 - Número de citações em Antropologia e Psicologia}

\begin{tabular}{|l|l|r|l|l|l|}
\hline Disciplina & $\begin{array}{l}\text { No de } \\
\text { Artigos }\end{array}$ & $\begin{array}{l}\text { Total } \\
\text { de Palavras }\end{array}$ & $\begin{array}{l}\text { Média } \\
\text { Palavras/ } \\
\text { Artigo }\end{array}$ & $\begin{array}{l}\text { Total } \\
\text { d }\end{array}$ & $\begin{array}{l}\text { Médiações } \\
\text { Citação/ } \\
\text { Artigo }\end{array}$ \\
\hline Antropologia & 16 & 126.789 & 7.924 & 1.025 & 64 \\
\hline Psicologia & 16 & 110.762 & 6.920 & 1.292 & 81 \\
\hline
\end{tabular}

Os artigos de Antropologia são, em geral, mais longos que os de Psicologia, entretanto esta cita muito mais que a Antropologia: há uma média de 81 citações por artigo na Psicologia e 64 citações por artigo na Antropologia. A média de citações por artigo, no entanto, esconde a grande variação com respeito ao número de citações por artigo em cada disciplina. Esse número por artigo na Antropologia varia de 13 a 231, enquanto na Psicologia varia entre 21 e 138. Com a exceção de um artigo de Antropologia (com 231 citações) que faz uma revisão histórica de estudos sobre música indígena no Brasil, não há uma explicação óbvia para as diferenças na quantidade de citações contida nos artigos, tanto com referência às diferenças encontradas dentro de cada área quanto às diferenças entre as duas áreas. Se se descartar o artigo em Antropologia que tem 231 citações, então a média de citação por artigo baixa para 52, distanciando ainda mais da média para Psicologia. Suspeito que as diferenças se devem às razões pelas quais as duas áreas citam e o tipo de pesquisas discutido em cada área.

Para a análise da forma ou técnica de atribuição da citação, Swales (1990) oferece uma classificação que distingue duas estruturas básicas que denomina citações integrais e não-integrais. A distinção é 
sintática e facilmente percebida. Na citação integral, o nome do autor citado ocorre na oração citante, seja na posição de sujeito da oração, como em (1) e (2);

(1) Ginzburg (2001) realiza a melhor indagação sobre as numerosas fontes do sabbath europeu...,

(2) Georg Simmel (1977) também assevera que o dinheiro é um elemento...

seja na posição não-sujeito, exemplificado em (3) e (4):

(3) Uma outra consideração neste sentido vem da perspectiva de Damásio (2000).

(4) O teste foi adaptado no Brasil por Biaggio (1989).

$\mathrm{Na}$ citação não-integral, o nome do autor citado não se materializa na oração citante; a referência ao autor aparece entre parênteses ou através de sistema numérico que remete a notas, como visto em (5) e (6). ${ }^{3}$

(5) Necessidades individuais de dominação e de controle podem também ser transformadas em valores relativos ao poder (Schwartz, 1992).

(6) Há consenso na literatura sobre a existência de uma forte correlação entre a qualidade das relações conjugais e parentais (Belsky, 1981, 1984; Brody, Pellegrini \& Sigel, 1986; Erel \& Burman, 1995; Gottman, 1993, 1998; Kreppner \& Ullrich, 1998).

Tanto os periódicos de Antropologia como os de Psicologia usam o sistema autor-data entre parênteses para as referências. Em

3. Tanto a Antropologia como a Psicologia usa o sistema autor/data entre parênteses, não recorrendo ao sistema numérico mais comum nas Ciências Exatas e na História. 
geral, as notas de rodapé são usadas para explicações não consideradas centrais ao texto. A Antropologia, no entanto, usa extensivamente notas de rodapé onde também faz citações, tanto integrais como não-integrais. Dos 16 textos analisados, todos continham notas de rodapé, variando entre 1 e 52 notas, com a média de 18 notas por artigo. Já a Psicologia faz pouco uso de notas de rodapé, uma vez que foram constatadas em apenas 5 dos 16 textos da amostra. Ressalte-se ainda que destes cinco apenas três traziam citações nas notas.

Em Antropologia, como pode ser visto na Tabela 2, há uma ligeira preferência para as citações integrais com 56\% vs 44\% para as não-integrais, enquanto na Psicologia a preferência é para as citações não-integrais $(67 \%)$ com apenas $33 \%$ para as integrais.

\section{Tabela 2: Formas de citação integral e não integral por disciplina}

\begin{tabular}{|c|c|c|c|c|c|}
\hline \multirow{2}{*}{ Disciplina } & \multirow{2}{*}{$\begin{array}{c}\text { Total Geral } \\
\text { de Citações }\end{array}$} & \multicolumn{2}{|c|}{ Citações Integrais } & \multicolumn{2}{|c|}{$\begin{array}{c}\text { Citações } \\
\text { Não-integrais }\end{array}$} \\
\cline { 3 - 6 } & & $\mathbf{N}^{\mathbf{o}}$ & $\%$ & $\mathbf{N}^{\mathbf{0}}$ & $\%$ \\
\hline Antropologia & 1025 & 578 & 56,0 & 447 & 44,0 \\
\hline Psicologia & 1.292 & 432 & 33,0 & 860 & 67,0 \\
\hline
\end{tabular}

Os estudos (Hyland, 1999, 2000; Swales, 1990) sobre as práticas de citação atribuem o uso de uma forma ou de outra a uma decisão do escritor citante para dar mais ênfase ao autor citado ou a mensagem citada. Estes estudos também revelam pouco uso da citação integral nas Ciências Exatas e, embora seu emprego seja maior nas Ciências Humanas e Sociais, na maioria dos casos nessas também há maior emprego das citações não-integrais (cf. Swales, 1999, 2000; Hyland, 2000; Thompson \& Tribble, 2001). Hyland (1999:355) sugere que a predominância da citação não-integral na escrita acadêmica está relacionada à tradição da epistemologia positivista que busca suprimir a agência humana na construção do conhecimento.

A nomeação, segundo alguns estudiosos das práticas de citação (cf. Paul, 2000; Hyland, 1999), favorece um sentido de comunidade 
e indica que o escritor citante acredita que o nome citado será reconhecido como um nome de valor. A citação deste nome significa reunir-se a ele, demonstrando um ethos de respeito e credibilidade. O pouco uso da citação integral reportado para as Ciências Exatas (Hyland, 1999; 2000; Paul, 2000; entre outros) é atribuído à ênfase que é dada ao trabalho científico antes que aos indivíduos que fazem o trabalho. Essa prática também reforça a idéia tradicional da ciência como algo objetivo e impessoal.

Nas citações integrais, a posição sintática do nome do autor citado reflete uma escolha retórica que modera o destaque dado ao autor, ou seja, a citação que coloca o nome do autor citado na posição de sujeito da oração reforça ainda mais o reconhecimento do autor citado, enquanto a posição não-sujeito dá mais ênfase às idéias ou aos conceitos deste autor.

A Tabela 3 mostra a frequência das citações integrais com autor-sujeito e autor não sujeito. A posição do autor-sujeito é mais freqüente em Psicologia e a posição autor/não-sujeito é mais frequente em Antropologia. Esses resultados contradizem a literatura que sugere que a posição não-sujeito é mais comum em todas as áreas de conhecimento. É interessante observar que, em geral, a Psicologia faz menos citações integrais (apenas 33\%), mas quando faz as citações integrais, coloca o autor citado em destaque mais frequentemente do que os conceitos destes autores.

\section{Tabela 3. Posição sintática do autor nas citações integrais por disciplina}

\begin{tabular}{|c|c|c|c|c|c|}
\hline \multirow{3}{*}{ Disciplinas } & \multicolumn{4}{|c|}{ Citações Integrais } & \multirow{3}{*}{$\begin{array}{c}\text { Total geral } \\
\text { de citações } \\
\text { integrais }\end{array}$} \\
\hline & \multicolumn{2}{|c|}{ Autor/sujeito } & \multicolumn{2}{|c|}{ Autor/não-sujeito } & \\
\hline & $\mathbf{N}^{\circ}$ & $\%$ & $\mathbf{N}^{\mathbf{o}}$ & $\%$ & \\
\hline Antropologia & 259 & 45,0 & 319 & 55,0 & 578 \\
\hline Psicologia & 238 & 55,0 & 194 & 45,0 & 432 \\
\hline
\end{tabular}


A estrutura da citação integral/autor não-sujeito é geralmente expressa de três maneiras: por meio da forma passiva do verbo exemplos (7), (8); de construções adverbiais - exemplos (9), (10); e do que Marcuschi (2007:147) chama de nominalização ${ }^{4}$ - exemplos (11), (12). Como comentado acima, a citação integral dá destaque ao autor citado uma vez que seu nome aparece no texto, mas este destaque é relativo à posição sintática que o nome ocupa.

\section{Forma passiva:}

(7) Tal sentido de tradução aproxima-se daquele preconizado por Benjamin (1968)

(8) Tendo em conta os antecedentes da luta camponesa na região, descritos, entre outros, por Marulanda (1991:74) e Londoño (1993:58-59)

Construções adverbiais:

(9) Para Blumer, isso equivale a colocar ambos os grupos em relação recíproca, definindo suas respectivas posições sociais.

(10) Ou seja, Taulipáng é, segundo Koch-Grünberg, a autodenominação de uma tribo do norte de Roraima,...

Nominalização de verbos:

(11) ... algo que se consolidou sobretudo com os trabalhos de Lewis (1951 e 1976[1965]), em contraposição às já mencionadas abordagens de Redfield

4. Usamos o termo de Marcuschi para incluir as formas que os estudos de citação em inglês chamam de possessive noun frases (Pickard 1995; Hyland 1999). 
(12) Essas atitudes se refletem nas intuições de Echeverría e no trabalho de María Victoria Uribe anteriormente citados.

Das três formas de citação integral/autor não-sujeito, a nominalização foi mais usada nas duas disciplinas (Antropologia $55 \%$, Psicologia 42\%) como se pode ver na Tabela 4. A escolha das outras duas formas foi bastante equilibrada na Psicologia com $28 \%$ para a forma passiva e $30 \%$ para as construções adverbiais. Antropologia usa a forma passiva (25\%) com mais frequência que a construção adverbial $(20 \%)$.

\section{Tabela 4: Frequência das formas de passiva, nominalização e adverbial em citações integrais autor/não-sujeito}

\begin{tabular}{|l|r|r|r|r|r|r|r|}
\hline \multirow{2}{*}{ Disciplina } & \multicolumn{2}{|c|}{$\begin{array}{c}\text { Forma } \\
\text { Passiva }\end{array}$} & \multicolumn{2}{|c|}{ Nominalizações } & \multicolumn{2}{|c|}{$\begin{array}{c}\text { Construções } \\
\text { Adverbiais }\end{array}$} & \multirow{2}{*}{ Total } \\
\cline { 2 - 6 } & $\mathrm{N}^{\mathrm{N}}$ & $\%$ & $\mathrm{~N}^{\mathrm{o}}$ & $\%$ & $\mathrm{~N}^{\mathrm{o}}$ & $\%$ & \\
\hline Antropoogia & 81 & 25 & 174 & 55 & 64 & 20 & 319 \\
\hline Psicologia & 66 & 28 & 99 & 42 & 73 & 30 & 238 \\
\hline
\end{tabular}

\section{Paráfrase ou citação direta}

Como escritores escolhem incorporar o trabalho do outro ao seu texto consiste em outra decisão retórica que o escritor precisa fazer. As possibilidades vão de uma mera menção ao trabalho a uma extensiva discussão sobre ele. Hyland (2000:26) sugere que a escolha "têm um impacto importante na expressão de relações sociais na construção colaborativa de um argumento plausível”. A questão é até que ponto a citação reproduz o material original. As opções incluem pequenas citações diretas (de uma a duas palavras isoladas ou de uma a duas linhas - exemplo (13); citações direitas extensivas e, normalmente, destacadas do texto em forma de um 
bloco - exemplo (14); paráfrase na forma de um resumo de uma única fonte - exemplo (15), ou na forma de uma generalização, onde o material citado é atribuído a dois ou mais autores - exemplo (16).

\section{Citação direta curta}

(13) Quando se enuncia "saúde para todos em 2000", como na Assembléia Mundial de Saúde no ano de 1977, ou "adicionar não só anos à vida, mas vida aos anos" (Paim \& Almeida Filho, 2000:44)

\section{Citação direita longa}

(14) Quando Park introduz o livro de Pierson ao público americano é muito claro em apontar o significado do Brasil como laboratório de relações raciais: Fato que torna interessante a "situação racial" brasileira é que, tendo uma população de cor proporcionalmente maior que a dos Estados Unidos, o Brasil não tem "problema racial”. Pelo menos é o que se pode inferir das informações casuais e aparentemente desinteressadas de visitantes desse país que indagaram sobre o assunto [referindo-se a James Bryce e Theodore Roosevelt] (Park, 1971, p. 83).

\section{Resumo}

(15) Por exemplo, o conceito de cidadania relacionado à saúde, conforme Luz (1991), foi visibilizado mediante o movimento da sociedade civil organizada, no final da década de 1980

\section{Generalização}

(16) Diversos autores (Durlak \& Wells, 1997; Lane \& Beebe-Frankenberger, 2004; Meschke \& Patterson, 2003; 
Shochet et al., 2001) têm defendido que os programas preventivos

A opção para a paráfrase (seja na forma de resumo ou de generalização) parece ser o padrão na Psicologia. A citação direta foi pouco recorrente, com 22 ocorrências, todas curtas. Dos 16 artigos examinados, apenas 06 apresentaram citações diretas. Já na Antropologia, embora a paráfrase prevaleça sobre a citação direta, encontramos 112 citações diretas, na sua maioria, relativamente longas; não ocorrendo citações diretas em apenas dois dos artigos.

Hyland (1999, 2000), cujos estudos examinaram a prática da citação acadêmica em inglês para oito diferentes disciplinas afirma que como um escritor apresenta o trabalho do outro é crucial para conseguir aceitação de suas alegações. Uma vez que na paráfrase, através de resumo ou de generalização, escritores tendem a expressar o material original nos seus próprios termos, essa forma permite que o escritor tenha mais flexibilidade para enfatizar, comentar, criticar, interpretar os textos que cita. Hyland ainda alega que as palavras originais do autor citado só são levadas ao novo texto se o escritor considere que esta seja a maneira mais efetiva de apresentar seu argumento 5 .

Vários pesquisadores já indicaram que o uso relativo de citações diretas ou parafraseadas parece separar os escritores experientes dos menos experientes (Pickard, 1995; Dionísio, 2001). . Dionisio (2001), por exemplo, numa investigação do uso de citações em textos acadêmicos (resenhas, artigos e monografias) de alunos e professores de português, encontrou um índice de paráfrases bem inferior ao de citações diretas nas monografias escritas por alunos. Isso, segundo a autora, demonstra uma falta de habilidade na parte dos alunos em se posicionaram frente ao conteúdo temático dos trabalhos que citam.

5. Se essa afirmação de Hyland aplica ao caso de Antropologia cujo uso da citação direta é aquém do esperado (de acordo com a literatura) para autores proficientes, seria necessária uma investigação dos motivos para a citação junto aos autores. 


\section{Verbos de citação}

Nas citações integrais, diretas ou parafraseadas, o discurso citado é introduzido ou apresentado pelo escritor citante através de verbos de citação (também chamados de verbos de elocução ou verbos de relato). A escolha do verbo, como outros aspectos da citação já discutidos, é também uma escolha retórica. Analiso, a seguir, os padrões de uso dos verbos de citação.

Os verbos de citação, na forma ativa ou passiva, usados nas citações integrais para introduzir as informações citadas funcionam nas palavras de Marcuschi (2007:148), como parafraseamentos sintéticos, uma vez que "eles resumem em uma só palavra o sentido geral do discurso a relatar." Para Maingueneau (2001:150), a escolha do verbo introdutor da citação é importante, uma vez que "condiciona a interpretação, dando um certo direcionamento ao discurso citado.” Isto é, a escolha do verbo de citação evidencia mais claramente o posicionamento ou avaliação do escritor citante (grau de aceitação, rejeição ou neutralidade) frente ao material citado.

É impressionante a variedade de verbos de relato usados nas duas áreas investigadas. Embora fossem usados 135 verbos diferentes nos artigos de Antropologia e 90 nos de Psicologia, em ambos os casos em torno de $50 \%$ destes verbos foram empregados uma única vez no corpus. Por outro lado, cada área demonstrou ter alguns verbos preferidos (Tabela 5). Por exemplo, enquanto o verbo dizer foi o mais usado em artigos de Antropologia, não aparece nos artigos de Psicologia, ao passo em que o verbo mais empregado na Psicologia (realizar) ocorreu somente duas vezes na Antropologia. Apenas cinco verbos (afirmar, apontar, mostrar, propor, sugerir) estão entre os verbos mais utilizados nas duas áreas investigadas, embora com ocorrências diversas. Os verbos mais frequentes representam, em cada área, um terço das ocorrências dos verbos de citação. 


\section{Tabela 5. Verbos mais frequentes nas citações integrais (até 5 ocorrências)}

\begin{tabular}{|l|l|l|l|}
\hline Antropologia & $\mathbf{N}^{\mathbf{0}}$ & Psicologia & $\mathbf{N}^{\mathbf{0}}$ \\
\hline Dizer & 18 & Realizar & 19 \\
\hline Afirmar & 14 & Observar & 12 \\
\hline Citar & 13 & Propor & 9 \\
\hline Apontar & 12 & Sugerir & 9 \\
\hline Mostrar & 12 & Apontar & 8 \\
\hline Analisar & 8 & Verificar & 7 \\
\hline Defender & 8 & Mostrar & 7 \\
\hline Fazer & 8 & Constatar & 7 \\
\hline Sugerir & 6 & Considerar & 5 \\
\hline Chamar & 5 & Afirmar & 5 \\
\hline Propor & 5 & Destacar & 5 \\
\hline & & Obter & 5 \\
\hline
\end{tabular}

Esses achados, com respeito à constatação da grande variedade de verbos empregados e das aparentes preferências para certos verbos em cada área disciplinar, estão parcialmente em consonância com os resultados reportados para os estudos em inglês (cf. Hyland, 1999) e também com o estudo de Cortes (2009) que investigou os usos nas áreas de História e Sociologia em português.

Um último aspecto a ser considerado são os tipos de atividades aos quais os verbos de citação se referem. Adotando a proposta de Hyland (1999), os verbos podem ser classificados em três processos: (1) atos de pesquisa que ocorrem em declarações sobre resultados (observar, descobrir, notar, mostrar, etc.) ou procedimentos (analisar, calcular, explorar, examinar, estabelecer, etc) de pesquisa; (2) atos de cognição, referentes aos processos mentais (acreditar, pensar, 
conceituar, considerar, ponderar, ver, entender, teorizar suspeitar, etc.); e (3) atos de discurso ${ }^{6}$, verbos que envolvem a expressão verbal (dizer, discutir, escrever, declarar, expor, afirmar, argumentar, assinalar, propor, nomear, descrever, etc.).

Os três processos são encontrados nos artigos das duas disciplinas. Enquanto os atos de discurso prevalecem na Antropologia, na Psicologia são mais comuns os atos de pesquisa. Já os atos de cognição são menos recorrentes em ambas. Restringindo nossa análise aqui para os verbos mais empregados (cf. Tabela 5), verifica-se que verbos que se referem aos atos de discurso encabeçam a lista de Antropologia (dizer, afirmar), enquanto os dois verbos mais frequentes (realizar, observar) nos artigos de Psicologia remetem a atos de pesquisa. Os verbos relacionados aos atos de discurso representam 69\% das ocorrências em Antropologia vs 35\% em Psicologia, enquanto os de atos de pesquisa representam 59\% das ocorrências em Psicologia vs 37\% em Antropologia?.

Esses resultados implicam que as duas áreas utilizam a citação, proporcionalmente, para fins diferentes. As diferenças têm a ver com a organização retórica dos artigos. Os artigos da Psicologia, na sua maioria, relataram pesquisas experimentais e dedicaram um espaço textual considerável para situar a pesquisa relatada em um contexto de pesquisas anteriores semelhantes e para descrever os métodos e procedimentos usados, fazendo muitas referências aos estudos anteriores que tratavam do mesmo tema ou utilizaram os mesmos procedimentos. Os artigos em Antropologia dedicavam pouco espaço à contextualização da pesquisa e quando houve a descrição da metodologia usada na pesquisa era em termos muito

6. Cortes (2009:70ss) divide essa categoria em dois: verbos indicadores de afirmação e verbos indicadores de argumento. Essa divisão permite uma análise mais detalhada da ação retórica dos verbos dessa categoria .

7. A classificação dos verbos na lista de Tabela 5 como referindo a atos de discurso (dizer, afirmar, citar, constatar, defender, destacar, sugerir, chamar, propor) atos de pesquisa (realizar, analisar, fazer, observar, apontar, verificar, mostrar, obter) e atos de cognição (considerar) é apenas um procedimento metodológico que reflete o uso mais comum destes verbos. Uma investigação mais detalhado do contexto de cada ocorrência, com certeza, revelaria usos do mesmo verbo com sentidos distintos. 
gerais ("um estudo etnográfico"), não suscitando referências a trabalhos ou autores específicos. A organização retórica dos artigos de Antropologia é parecida com a de História descrita por Holmes (1997:328). Este autor atribui essa diferença "à preocupação da disciplina em fornecer explicações de eventos discretos em vez da descoberta de padrões generalizáveis”. A maioria dos textos em Antropologia também relatava eventos discretos através de uma estrutura textual mais narrativa onde a citações, em grande parte, visavam travar um diálogo com os autores citados.

\section{Considerações finais}

Pode-se dizer que a citação de trabalhos anteriores é obrigatória na escrita acadêmica. Mas não pode dizer que a citação é uma atividade simples, pois requer escolhas retóricas nada simples. O escritor, além de decidir quando deve citar e quem deve citar (e não citar), tem que decidir como incorporar o material citado (citação direta ou parafraseada), e como apresentar o autor/trabalho citado (por exemplo, a escolha do verbo de citação). Além disso, este escritor tem que fazer todas essas escolhas retóricas de acordo com as convenções para a escrita acadêmica de sua área disciplinar. Pois, como Hyland (1999:363) nos lembra "O fato de que acadêmicos se engajam ativamente na construção do conhecimento como membros de grupos profissionais significa que suas decisões discursivas são ancoradas socialmente, influenciadas pelos padrões gerais de investigação e pelas estruturas de conhecimento de suas disciplinas”.

Os resultados da nossa análise das práticas de citação em artigos de Psicologia e Antropologia revelaram diferentes padrões de citação. Esses resultados são compatíveis com os resultados do estudo de Cortes (2009) que encontrou diferenças nas práticas de citação entre as disciplinas de História e Sociologia. É provável que uma investigação das práticas em outras disciplinas também revelaria padrões específicos a cada uma. 
Espera-se que essa investigação, além de revelar as diferentes práticas de citação em uso, sirva para mostrar que essa atividade retórica é uma parte importante da escrita acadêmica. Como tal, deve ser incluída em qualquer programa de ensino da produção textual. $\mathrm{O}$ aluno que entende o papel cultural e linguístico da citação estará melhor preparado para escrever textos acadêmicos em sua área de estudo.

Recebido em: maio de 2009 Aprovado em: junho de 2009 hoffnagel@uol.com.br

\section{Referências Bibliográficas}

ALLEN, B; QIN, J.; LANCASTER, F.W. Persuasive communities: A longitudinal analysis of rferences in the Philosofical Transactions of the Royal Society - 1665-1990. SOCIAL STUDIES OF SCIENCE vol. 24, 1994, p. 279-310

BAZERMAN, C. Shaping Written Knowledge The Genre and Activity of the Experimental Article in Science. Madison: The University of Wisconsin Press, 1988

BERKENKOTTER, C. \& HUCKIN, T.N. Genre Knowledge in Disciplinary Communication: Cognition/Culture/Power. Hillsdale, NJ: Lawrence Erlbaum, 1995

CORTES, G.R. de O. Práticas sócio-retóricas do gênero artigo científico de História e Sociologia: variação, identidade e ethos disciplinar. Dissertação de Mestrado. Recife: Universidade Federal de Pernambuco, 2009

DIONISIO, A.P. Formas de referenciação a autores em textos acadêmicos produzidos por alunos e professores de português. INVESTIGAÇÕES: LINGUÍSTICA E TEORIA LITERÁRIA. Recife: vol.13, 2001, p. 233-245. 
HOLMES, R.. Genre analysis and the Social Sciences: An investigation of the structure of research article discussion sections in three disciplines. ENGLISH FOR SPECIFIC PURPOSES. vol. 16(4): 1997, p. 321-337.

HYLAND, K. Disciplinary Discourses: Social Interactions in Academic Writing. London: Longman, 2000.

HYLAND, K. Academic attribution: Citation and the construction of disciplinary knowledge. APPLIED LINGUISTICS. vol. 20(3), 1999, p. 341-367.

MAINGUENEAU, D. Análise de textos de comunicação. São Paulo: Contexto, 2001

MARCUSCHI, L.A. A ação dos verbos introdutórios de opinião. In Fenômenos da linguagem: Reflexões semânticas e discursivas. Rio de Janeiro: Lucerna, 2007

PAUL, D. In citing chaos: A study of the rhetorical use of citations. JOURNAL OF BUSINESS AND TECHNICAL COMMUNICATION. vol. 14, 2000, p. 185-222.

PICKARD, V. Citing previous writers: What can we say instead of 'say'? HONG KONG PAPERS IN LINGUISTS AND LANGUAGE TEACHING. vol. 18, 1995, p. 89-102.

SWALES, J. Genre Analysis: English in academic and research settings. Cambridge: Cambridge University Press, 1990.

THOMPSON, P. \& TRIBBLE, C. Looking at citations: using corpora in English for academic purposes. LANGUAGE LEARNING \& TECHNOLOGY. 5(3), 2001, p. 91-105. 